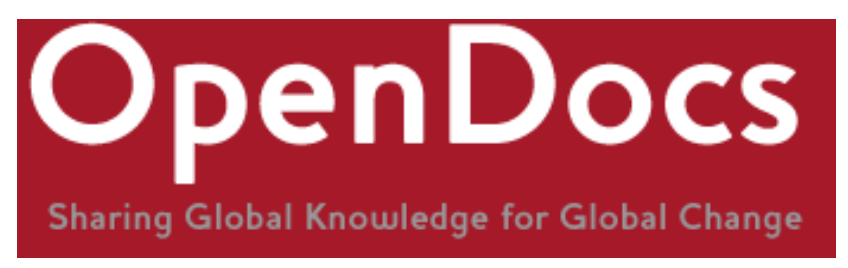

Title: Citizen engagements in a globalizing world

Citation: Gaventa, J. and Tandon, R. (2010) Citizen engagements in a globalizing world. In: Gaventa, J. and Tandon, R. (eds.) In: Globalizing Citizens: New Dynamics of Inclusion and Exclusion. London: Zed Books, pp. 3-30.

Official URL: https://www.zedbooks.net/shop/book/globalizing-citizens/

More details/abstract: This chapter is the introduction to a book which presents expert analysis from cities and villages in India, South Africa, Nigeria, the Philippines, Kenya, the Gambia and Brazil to explore how forms of global authority shape and build new meanings and practices of citizenship, across local, national and global arenas. Owing to copyright restrictions, only the first 3 pages are attached, together with a link to the book at Zed Books.

Version: Published version

Terms of use: Due to copyright restrictions, we can only share the first three pages of this chapter online. The book can be ordered from Zed Books at https://www.zedbooks.net/shop/book/globalizing-citizens/

This is a download from OpenDocs at the Institute of Development Studies

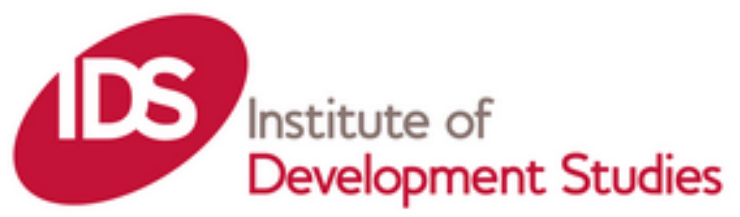




\title{
1. Citizen engagements in a globalizing world
}

\author{
JOHN GAVENTA AND RAJESH TANDON ${ }^{1}$
}

\section{Introduction}

From Cancún to Copenhagen, from trade debates to climate debates and from financial crises to food crises, the impacts of global forces on everyday life are becoming increasingly apparent. With globalization have come changing forms of power and new realms of authority, and with these, new spaces for public action. From local to global, fields of power and landscapes of authority are being reconfigured, affecting the lives and futures of citizens across the planet, while simultaneously reshaping where and how citizens engage to make their voices heard. If we believe in the ideals of democracy, in which citizens have the right to participate in decisions and deliberations affecting their lives, what are the implications when these extend beyond traditionally understood national and local boundaries? If we are interested in the possibilities of citizen action to claim and ensure rights, and to bring about social change, how do citizens navigate this new, more complicated terrain? What are the consequences for an emerging sense and experience of global citizenship, and for holding governments and powerful supranational institutions and authorities to account?

While a great deal of attention has been paid in the literature to these changing patterns of global governance, we know remarkably little about how they play out, or their consequences and implications for ordinary citizens. In this volume, this theme is explored through empirical research in Brazil, India, the Gambia, Nigeria, the Philippines and South Africa, as well as in cross-national projects in Latin America and Africa. The case studies focus on a number of sectors: the environment, trade, education, livelihoods, health and HIV/AIDS, work and occupational disease, agriculture and land. ${ }^{2}$ They document different types of engagement, ranging from transnational campaigns and social movements to participation in new institutionally designed fora. Taking a citizen's perspective, they look upwards and outwards at shifting global forms of authority and ask whether, in response to these governance changes, citizens themselves are expressing new rights 
claims on global duty holders, and whether they are expressing new forms of global solidarity with citizens in other localities.

There are a number of possible responses to these questions. On the one hand, some scholars have argued, globalization has led to changes in governance and emerging transnational social movements which are creating new spaces and opportunities for citizen engagement. In the process, as citizenship has become delinked from territorial boundaries, it has also become more multilayered and multi-scaled, while governance increasingly involves both state and non-state actors, many of which are transnational. The new global configuration, some optimistically argue, provides the conditions for the ascendancy of a new sense of global citizenship, which deepens and expands democratic participation and the realization of human rights.

The case studies in this volume, however, collectively present a somewhat more sombre picture. While shifting landscapes of global authority create new spaces and opportunities for citizen engagement, they also carry with them new possibilities for and forms of power, which interact with deeply embedded local practices. For some citizens, there are new opportunities for participation in transnational processes of action, resulting in the emergence of a new sense of global citizenship and solidarity. Yet for many other ordinary citizens, changes in global authority may have the opposite effect, strengthening the layers and discourses of power that limit the possibilities for their local action, and constraining - or, at least, not enabling - a sense of citizen agency. Even in these cases, however, one can see localized patterns of resistance to global forces, motivated by immediate issues of survival and fragility, rather than a virtuous sense of global solidarity and citizenship.

In the first section of this introductory chapter, we bring together empirical insights from the case studies on how changing global governance patterns affect the possibilities for and arenas of citizen engagement. Sometimes they create new spheres for engagement beyond the nation-state; at other times they bring global factors to bear on national and local forms of action. Contrary to some assertions made in the literature, we find that globalized governance does not necessarily imply a diminishing role for the nation-state. Rather, globalization adds new layers, arenas and jurisdictions of governance, often bringing contestation and competition across them rather than the replacing of one arena with another.

We move on to discuss ways that the multi-tiered and multipolar character of global authority simultaneously creates new multilayered and multidimensional identities of citizenship, which in some cases 
create new possibilities for inclusive citizen voice, while in others serve to reinforce axes for greater exclusion, contributing to the weakening of already fragile forms of citizen expression. In sum, there are winners and losers in this process.

In the next section we argue that explaining the difference in these outcomes involves exploring forms of mobilization, the role of mediators and the politics of knowledge which shape the possibilities and practices of citizenship in response to the changes in the global landscape. By examining these intervening factors, we can gain insights into the paradox of why, for some, globalization offers possibilities for a new sense of solidarity and new opportunities for engagement, while for others it offers little real opportunity for expanded solidarity, and weakens the possibilities for citizen agency.

We end this chapter by arguing that taking a 'vertical' approach - one that looks at the interrelationships of levels of authority along a scale running from local to global - has important strategic implications for citizen action and social movements. In this interdependent world, more inclusive citizenship, and with it more effective forms of citizen engagement, will not be realized by a focus on one arena or layer of political authority alone. Rather, more promise is found in new forms of engagement which recognize the layers of authority and employ strategies that build citizen solidarity vertically and synergistically across them.

\section{The changing nature of governance: new spaces for citizen engagements?}

It is now commonplace in emerging literature on globalization and governance to argue that authority is moving beyond singular nationstate systems and power is increasingly dispersed along a scale from local to global, and across state and non-state actors. In this new emerging global order, governance is seen as a) multilayered (cutting across global, regional, national and local institutions), b) polyarchic or pluralistic (in the sense that no site of governance has unilateral, supreme and absolute authority), c) geometrically varied (in that regulatory systems vary across issues and geographies), and d) structurally complex (made up of diverse state and non-state agencies and networks) (Held and McGrew 2002: 9). Such shifts in global governance have important consequences for grassroots actors. They reshape the possibilities for extending their action to the international arena, as well as for citizen action more locally (Della Porta and Tarrow 2005; Edwards and Gaventa 2001; Keck and Sikkink 1998; Appadurai 2000). ${ }^{3}$

In every case in this volume, we see examples of how this shifting 